\title{
AS MULHERES ESTÃO QUEBRANDO AS TRÊS PAREDES DE VIDRO? UM ESTUDO COM EMPREENDEDORAS MINEIRAS
}

\section{ARE WOMEN BREAKING THE THREE GLASS WALLS ? A STUDY WITH ENTREPRENEURS FROM MINAS GERAIS, BRAZIL}

\author{
Carolina Maria Mota Santos \\ PPGA-PUCMinas \\ cmmotasantos@gmail.com \\ Antonio Carvalho Neto \\ PPGA-PUCMinas \\ carvalhoneto@pucminas.br \\ Mariana Caeiro \\ PPGA-PUCMinas \\ mariana-caeiro@hotmail.com \\ Fernanda Versiani \\ PPGA-PUCMinas \\ nandaversiani@gmail.com \\ Mariana Geisel Martins \\ CEFET-MG) \\ marianagmartins@hotmail.com
}

Submissão: 26/03/2016 Aprovação: 20/02/2017 
RESUMO

O objetivo deste artigo é identificar as possíveis paredes de vidro (barreiras) encontradas pelas mulheres empreendedoras na condução dos seus negócios e suas estratégias para quebrar essas paredes. Trata-se de uma pesquisa qualitativa descritiva com 25 mulheres que empreenderam há, pelo menos, 5 anos. O referencial teórico explora as barreiras encontradas por mulheres empreendedoras a partir de Jonathan $(2005 ; 2011)$. Além disso, trata de uma terminologia bastante utilizada para conceituar as barreiras na área da administração: Glass Ceiling (Steil, 1997; Mota Santos, Tanure, Carvalho Neto, 2014; Carvalho Neto, Tanure, Mota-Santos, 2014) e explora outra terminologia pouco retratada pela literatura: Glass Walls (Miller, Kerr, Reid, 1999). Para o tratamento dos dados, foi utilizada a técnica de análise de conteúdo. Os resultados da pesquisa indicaram três paredes que cercam a carreira da mulher empreendedora: a primeira ocorre a partir da família, a segunda constituída por clientes, fornecedores e funcionários e, a terceira representada pela sociedade de maneira geral, ou seja, contempla pessoas que não se relacionam diretamente com a empreendedora, como vizinhos e proprietários de outros empreendimentos. Apesar destas paredes, o reconhecimento e a independência financeira influenciam essa dinâmica de forma positiva.

Palavras-chave: Parede de vidro; Mulheres empreendedoras; Barreiras; Reconhecimento social. 


\begin{abstract}
The purpose of this article is to identify possible glass walls to women entrepreneurs and their strategies to break these walls. This is a descriptive qualitative research with 25 women which are entrepreneurs for at least 5 years. The theoretical framework explores the barriers faced by women entrepreneurs from Jonathan $(2005 ; 2011)$. Moreover, this is a terminology often used to conceptualize the barriers: Glass Ceiling (Steil , 1997; Mota Santos, Tanure, Carvalho Neto, 2014; Carvalho Neto, Tanure , Mota- Santos, 2014) and explores another little portrayed terminology by literature: Glass Walls (Miller , Kerr , Reid , 1999). For the treatment of data it was used the technique of content analysis. The survey results indicated three walls surrounding the career of entrepreneurial women: the first is originated in the family; the second consisting of customers, suppliers and employees; and the third represented by the general society, that is, includes all persons that do not interact directly to the entrepreneur such as neighbors and owners of other businesses. Despite these walls, recognition and financial independence influence the dynamics in a positive way.
\end{abstract}

Key-words: Glass wall; Women entrepreneurs; Barriers; Social recognition 


\section{INTRODUÇÃO}

A barreira ao crescimento das mulheres nas organizações norte-americanas fez com que um termo fosse criado para representá-la: glass ceiling, teto de vidro. Teto de vidro é uma representação simbólica de uma barreira sutil e ao mesmo tempo forte que impede o crescimento feminino no ambiente organizacional (ANDRADE, 2010; DAVIDSON; COOPER, 1992; MOORE, BUTTNER, 1997; MORRISON, WHITE, VELSOR, 1994; MORRISON; GLINOW, 1990; NEWMAN, 1993; STEIL, 1997; WRIGHT; BAXTER, 2000).

Há pelo menos duas vertentes que buscam explicitar a existência do fenômeno teto de vidro na literatura. Uma enfatiza a diferença comportamental entre mulheres e homens e a outra a discriminação (COELHO, 2006). Em relação a presença do teto de vidro nas organizações americanas, Brown (2010) sugere dois valores chamados de internos e externos que podem contribuir para aumentar a barreira que evita o crescimento das mulheres. Os internos estão relacionados às opiniões que as mulheres têm de si mesmas e são os dominantes; e os externos são as opiniões que os homens têm das características das mulheres. Os homens, por exemplo, ainda acreditam que o comprometimento maior da mulher deve ser com a família (DAVIESNETZLEY, 1998).

Pesquisas sobre o fenômeno teto de vidro estão presentes na área da Administração desde a década de 1990, a partir dos estudos de Steil (1997). O fenômeno é estudado em relação às mulheres executivas brasileiras (MOTA SANTOS; TANURE; CARVALHO NETO 2014; CARVALHO NETO; TANURE; MOTA-SANTOS, 2014; LIMA et al, 2013) independente da função e, também, na área contábil (SOUZA; VOESE; ABBAS, 2015; SILVA; DAL MAGRO, SILVA, 2016).

Além do teto de vidro, existe outra terminologia que define os obstáculos que podem impedir o acesso de mulheres a certos departamentos. Trata-se do fenômeno parede de vidro. Este termo trata das dificuldades na mobilidade horizontal feminina dentro das organizações (MILLER, KERR; REID, 1999).

As terminologias, portanto, são utilizadas para descrever a segregação vertical e horizontal, ou seja, formas de dificultar a mobilidade profissional (BOTELHO; MACEDO; FIALHO, 2010). O termo glass ceiling (teto de vidro) se refere à segregação vertical, e o termo glass wall (parede de vidro), faz referência à segregação horizontal. A terminologia glass wall ou parede de vidro será utilizada neste trabalho uma vez que o que se busca aqui é compreender 
como as empreendedoras na cidade de Belo Horizonte estão combatendo as barreiras à sua carreira, ou seja, não se trata de uma dificuldade na mobilidade vertical, uma vez que essas mulheres não estão em cargos de empresas privadas buscando um crescimento vertical, mas sim um reconhecimento enquanto empreendedoras. Por isso, ocorre a analogia com a mobilidade horizontal.

A pesquisa sobre o empreendedorismo feminino já não é tão escassa, pelo menos quando se pensa na produção científica estrangeira. Muitas publicações nacionais enfocam questões relativas à biologia do sexo e não aprofundam em análises das relações culturais e sociais. Muitas vezes, a restrição é em nomear atributos femininos e também discutir de forma superficial as supostas características femininas em oposição às masculinas (GOMES; SANTANTA; ARAÚJO, 2009).

Logo, o objetivo deste artigo é identificar as possíveis paredes de vidro (barreiras) encontradas pelas mulheres empreendedoras na condução dos seus negócios e suas estratégias para quebrar essas paredes. A pergunta que norteou este trabalho foi: as mulheres empreendedoras encontram barreiras para a carreira empreendedora pelo fato de serem mulheres?

O referencial está dividio em duas partes. A primeira parte retrata os espaços compartilhados por homens e mulheres dando enfoque ao contexto atual onde a mulher ocupa espaços para além do lar. A segunda parte aborda os fenômenos glass ceiling e glass wall.

\section{EXISTEM PAPÉIS DE HOMENS E PAPÉIS DE MULHERES?}

Durante o período colonial, marcado fortemente pelo patriarcalismo, era destinado às mulheres apenas o espaço da casa. A elas cabia o cuidado com os filhos, com a família e com a manutenção da ordem do lar. Apenas no final do século XIX ocorre o surgimento de escolas de magistério, com a proposta de formar mulheres para serem professoras, pois esta era a única profissão aceitável para mulheres de classe média (ROCHA-COUTINHO, 1994). Até nos dias de hoje, como a educação, a área da saúde é considerada um tradicional gueto profissional feminino (ABRAMO, 2000; BRUSCHINI, 2000; BRUSCHINI; LOMBARDI, 2001).

Entre 1950 e 1980, coincidindo com o período de industrialização brasileiro e com as ondas feministas em todo o mundo, era possível observar um número relativamente alto de mulheres nas fábricas, ofertando sua mão-de-obra para um mercado que se encontrava em vasta expansão (ROCHA-COUTINHO, 1994). No entanto, merece destaque o fato de que as 
mulheres assumiam esses postos de maneira secundária, ou seja, sem concebê-lo como uma possibilidade de trabalho (MOTA-SANTOS; TANURE; CARVALHO NETO, 2015).

Tornar visível a mulher que foi ocultada foi o grande objetivo das estudiosas feministas. A invisibilidade produzida a partir de discursos que a colocavam no mundo doméstico, mundo este visto como único e verdadeiro para a mulher, passa a ser rompido não apenas por algumas mulheres estudiosas, mas também por mulheres de classes trabalhadoras e camponesas que há muito já exerciam tarefas fora do lar (LOURO, 2013).

Se os movimentos feministas quiseram por fim à divisão do que seria atividade de homem e o que seria de mulher, algumas feministas foram contra o modelo de semelhança, pois consideravam uma ameaça a especificidade feminina, ou seja, elas poderiam se conformar com o modelo masculino e assim perder suas próprias riquezas. Buscaram então valorizar as características femininas através do slogan: "a igualdade na diferença” (BADINTER, 1986). Foi a partir da década de 1980 que as mulheres firmaram sua posição no mercado de trabalho. Isso significa que elas deixaram de ocupar os postos de trabalho em caráter emergencial e passaram a, de fato, competir pelo espaço com os homens (MOTA-SANTOS; TANURE; CARVALHO NETO, 2015). Elas passam a ocupar posições de destaque nas diferentes esferas, assumindo papéis antes ocupados apenas pelos homens (VALE; SERAFIM, 2010).

Nesse sentido, será que ainda podemos dizer que existem espaços para as mulheres e espaços para os homens? DaMatta $(1986,1991)$ retratou o Brasil ao dizer dos espaços da casa e os espaços da rua. Também existiam mulheres das casas e mulheres das ruas, respectivamente as boas e as não tão "adequadas". Portanto, falar de espaço, falar de lugar também é falar de mulher.

Louro (2013) ressalta a importância de demarcar a diferença entre papéis e identidades. Papéis femininos e masculinos são padrões que uma sociedade cria para seus membros e que consequentemente definem seus comportamentos, uso de trajes e seu modo de comportar. Através do aprendizado destes papéis, conhecemos o que é adequado ou não para uma mulher e um homem. Na visão do autor, o grande desafio é entender o gênero como constituinte da identidade do sujeito. “... identidades que se transformam, que não são fixas ou permanentes, que podem, até mesmo, ser contraditórias" (LOURO, 2013, p.28).

Se a divisão entre homens e mulheres foi criada com o intuito de usar as diferenças como arma de dominação, isto é, como a dominação do masculino sobre o feminino (BEAUVOIR, 1980), hoje vemos homens mais envolvidos com os papéis do lar, antes dedicados apenas às mulheres. Vemos homens com atitudes mais femininas e vice versa. Hoje, 
as mudanças nos papéis de mães e pais e na estrutura familiar refletem em referências não tão estereotipadas de papéis.

A constituição da nova identidade, por exemplo, da mulher empresária, traz também modificações no contexto familiar (CRAMER et al, 2012). Hoje, o modelo tradicional da mulher-mãe e também da mulher-mãe-profissional toma formas mais fluidas em que não apenas ela, mas também os homens buscam suas próprias escolhas, modificando a qualquer momento suas opções para realizar sonhos e aspirações (BARBOSA; ROCHA-COUTINHO, 2012). Não podemos falar de apenas um tipo de mulher ou um tipo de homem. A verdade é que não podemos ignorar as especificidades quando se fala da categoria "mulher", que são elas: raça/etnia, geração, orientação sexual e classe, ou seja, não podemos mais falar "mulher" e sim “mulheres”(MELO, 2008).

As mulheres estão conquistando cada vez mais espaço no ambiente organizacional, entretanto, ainda existem desigualdades em relação ao masculino, o que acarreta um aumento de pesquisas sobre essa temática. Os estudos sobre gênero nas organizações brasileiras estão em uma fase embrionária (CAPPELLE et al, 2007), evidenciando que o campo ainda está em construção (ANDRADE; MACEDO; OLIVEIRA, 2014). Há possibilidade de pesquisa, mas também limitações que precisam ser superadas, como, por exemplo, explicação acerca de algumas questões que ainda não foram devidamente respondidas: Por que e como determinados elementos históricos, políticos e sociais vinculados ao gênero perpassam as práticas de gestão? Como a estrutura organizacional, as políticas e as práticas de gestão interferem na construção das diferenças de gênero? (CAPPELLE et al, 2007, p.24).

\section{PAREDES DE VIDRO: A REALIDADE DAS MULHERES EMPREENDEDORAS}

A atividade empreendedora ainda é vista como tipicamente masculina (MACHADO, 2012), evidência que comprova como o contexto sociocultural pode exercer uma força impeditiva para as mulheres no que se refere ao crescimento ou manutenção do empreendimento (TEIXEIRA; BOMFIM, 2016). Na carreira empreendedora, o preconceito contra a mulher começa na decisão desta de abrir um negócio e a acompanha durante sua jornada, inclusive nos conflitos entre a vida pessoal e a vida profissional (BOTELHO; MACEDO; FIALHO, 2010). Por ser uma posição originalmente masculina, ainda impõe muitas barreiras para serem quebradas pelas empreendedoras (CRAMER et al, 2012). 
Dentre as dificuldades impostas às empreendedoras, cabe citar: a falta de suporte por parte dos familiares, a falta de credibilidade dos bancos para financiamentos, empecilhos para atuar no mercado internacional e atitudes negativas de amigos, clientes e pessoas que estão envolvidas no trabalho da empreendedora (MACHADO, 2009). Esses fatores são algumas das paredes que as mulheres têm que quebrar a partir do momento em que decidem empreender e buscar reconhecimento pessoal e profissional, bem como independência financeira. Entretanto, outros estudos (BONFIM; TEIXEIRA, 2015) colocam a família não como um fator dificultador, mas, ao contrário, a família é vista como um apoio para superar as dificuldades.

Ao pesquisarem as dificuldades para as mulheres empreenderem, alguns estudos (FABRICIO; MACHADO, 2012; BARBOSA et al, 2011) ressaltam que dificuldades menos importantes estão associadas ao preconceito por ser mulher. Outros já aprofundam na discussão. De acordo com Machado (2012), o preconceito se transveste em descrédito a empreendimentos liderados por mulheres, principalmente em ramos considerados masculinos. A admiração vai ocorrer somente quando o negócio atinge fases mais sólidas.

Já em relação aos aspectos positivos, a maior satisfação das empreendedoras se deve ao ambiente do negócio próprio, que lhes proporciona reconhecimento social por tomar decisões importantes relacionadas aos negócios (KORN; FERRY, 2002), algo que lhes possibilita criar e afirmar seus próprios valores (BARBOSA et al, 2011).

Há, nas mulheres empreendedoras, um sentimento de orgulho e de vitória tanto pelo seu reconhecimento pessoal quanto pelo sucesso alcançado no desempenho de seus papéis. A alegria vem ao conquistar tanto a satisfação dos clientes quanto o reconhecimento do mercado de trabalho (JONATHAN, 2005). A escolha pelo empreendedorismo vem de uma busca proativa de independência e autorealização, mas também pela busca de significativas mudanças pessoais e profissionais (JONATHAN, 2011).

O reconhecimento enquanto implicação da carreira empreendedora para a mulher vai ao encontro do estudo de Betiol e Tonelli (1991). Apesar do estudo ter ocorrido com mulheres executivas, os autores observam que, ao longo da carreira, além do sofrimento, houve também sentimentos como felicidade, orgulho, realização, reconhecimento, desafio e aprendizado.

Um estudo realizado tanto com mulheres executivas quanto com empreendedoras (GOMES; GUERRA; VIEIRA, 2011) ressalta que o enfrentamento da dominação masculina é um desafio a mais a ser vencido e talvez a mais importante conquista. 


\section{METODOLOGIA}

A pesquisa que originou este artigo pode ser classificada como descritiva, uma vez que o tema das mulheres empreendedoras já tem algum acúmulo na literatura. Além disso, a definição por uma pesquisa do tipo descritiva justifica-se por ter objetivos bem definidos, procedimentos formais estudados e orientados para a solução de problemas ou avaliação de alternativas de cursos de ação (MATTAR, 1999). A pesquisa qualitativa foi a mais indicada, tendo como método o estudo de caso. O método de pesquisa de estudo de caso busca investigar temas complexos, que necessitam um "mergulho" de aprofundamento (YIN, 1994).

Foram entrevistadas 25 empreendedoras de diferentes segmentos na grande Belo Horizonte, com idades entre 31 a 69 anos e que possuíam empreendimentos com mais de 5 anos, pois, de acordo com Sebrae (2013), esse dado indica solidez do negócio já que nos dois primeiros anos de atividade as taxas de mortalidade são muito altas.

As entrevistas ocorreram no período de junho de 2014 a fevereiro de 2015 . O processo de escolha aconteceu por intermédio de indicações e por meio da técnica denominada snowball sampling, conhecida no Brasil como bola de neve. Os primeiros participantes da pesquisa indicam novos participantes que possuem o mesmo perfil pesquisado (VINUTO, 2014) ou seja, após uma entrevista era solicitado que a empreendedora indicasse outras empreendedoras que, por sua vez, também indicavam outras. Logo, a medida em que os participantes vão indicando outros, a amostra vai tomando forma até ser suficiente para concluir a pesquisa (VINUTO, 2014).

Os dados foram coletados por meio de entrevistas semiestruturadas. O roteiro da entrevista foi baseado: (1) na trajetória e razão para empreender; (2) nas barreiras e dificuldades para empreender; (3) no que motiva e desmotiva como empreendedora. As perguntas nasceram a partir destes três tópicos.

O tempo médio das entrevistas foi de 50 minutos. As entrevistas, em sua grande maioria, ocorreram nas empresas das empreendedoras e, em alguns casos, em suas casas. As entrevistas foram registradas com um gravador digital e posteriormente transcritas. $\mathrm{Na}$ análise dos dados, a seguir apresentada, optou-se por tratá-las apenas por "E" seguido do número correspondente à sua entrevista.

Após 12 anos de estudos sobre a carreira da mulher executiva, o grupo de pesquisa constituído pelos autores deste trabalho teve o interesse de investigar também a realidade das mulheres empreendedoras. As perguntas que fazem parte desta entrevista com as mulheres 
empreendedoras nasceram a priori, no entanto, como ressalta Trivinos (1987), as perguntas nascem da teoria que alimenta a ação do investigador, mas não apenas dela. Nascem também das informações recolhidas do fenômeno social, no caminho destes 12 anos de pesquisa.

Para o tratamento dos dados foi adotada a técnica de análise de conteúdo, que tem por objetivo sintetizar o material e analisá-lo utilizando categorias de análise (Flick, 2009). A análise do conteúdo do tipo categorial temática permitiu estabelecer duas categorias de análise: (1) as paredes de vidro e (2) os aspectos positivos que ajudam a diminuir as barreiras.

Na codificação definem-se as unidades de registro (BARDIN, 2011; DELLAGNELO; SILVA, 2005), que neste artigo foram os temas relativos às paredes de vidro. Bardin (2011) ressalta que as unidades de registro podem ser: a palavra, o objeto, o documento, o personagem e o tema. A unidade de registro aqui utilizada foi o tema, que consiste em descobrir o sentido que o autor deseja dar a uma mensagem e tem sido utilizado para o estudo de opiniões, crenças e motivações das pessoas (BARDIN, 2011; RICHARDSON, 2007). A categorização finaliza o processo de codificação (BARDIN, 2011; DELLAGNELO; SILVA, 2005). O critério de categorização utilizado neste estudo foi o semântico que se refere a agrupamentos de acordo com categorias temáticas (BARDIN, 2011), que consistem em isolar temas de um texto e extrair partes utilizáveis, de acordo com o problema pesquisado (RICHARDSON, 2007). A partir desta etapa as subcategorias foram divididas em (a) barreiras vindas das famílias; (b) barreiras constituídas por clientes, funcionários e fornecedores; e (c) barreiras representadas por vizinhos, amigos, proprietários de outros empreendimentos. Estas subcategorias fazem parte da primeira categoria de análise (1) paredes de vidro. As outras subcategorias: (a) dinheiro e (b) reconhecimento social fazem parte da segunda categoria de análise (2), sendo esses os aspectos positivos que ajudam a diminuir as barreiras.

\section{APRESENTAÇÃO E ANÁLISE DOS DADOS}

Os dados coletados foram divididos em duas categorias de análise relacionadas às barreiras identificadas neste trabalho como paredes de vidro e aos aspectos que contribuem para diminuí-las. A primeira parede está relacionada à família, a segunda é constituída por clientes, fornecedores e funcionários, e a terceira representada, entre outros, por vizinhos e proprietários dos demais empreendimentos. A outra categoria explorada neste trabalho tem relação com os aspectos positivos: o reconhecimento e a independência financeira, uma vez que estes dois conceitos perpassam a todo momento o discurso das empreendedoras ao relatarem as possíveis 
barreiras. O reconhecimento social e a independência financeira influenciam essa dinâmica de forma positiva, uma vez que fortalecem as mulheres no processo de quebra dessas paredes.

\subsection{Perfil das Entrevistadas}

Percebe-se que a grande maioria das empreendedoras é casada, possui curso superior e é mãe de pelo menos 2 filhos. Em relação à idade, a maior parte das entrevistadas (9) tem entre 41 a 50 anos. Há também um alto número entre as faixas 31 a 40 anos (7) e 51 a 60 anos (6). A empreendedora mais nova possui 31 anos e foram entrevistadas duas empreendedoras que estão com 69 anos. Há mais mulheres empreendedoras atuando nas áreas de Recursos Humanos, com eventos e na direção de restaurantes. Também foram pesquisadas empreendedoras nas áreas de serviço: transporte, academia, laboratório, imobiliária, escola de computação e de idiomas, agência de turismo e atendimento à idosos. O tempo de empresa varia de 5 a 25 anos, sendo que um número maior de empresas (11) está no mercado há 8 anos, conforme Tabela 1.

Tabela 1 - Perfil das empreendedoras

\begin{tabular}{|c|c|c|c|c|c|c|}
\hline $\begin{array}{c}\text { Entre- } \\
\text { vistadas }\end{array}$ & Idade & $\begin{array}{c}\text { Estado } \\
\text { civil }\end{array}$ & $\begin{array}{l}\text { Ramo de } \\
\text { atuação }\end{array}$ & Escolaridade & $\begin{array}{c}\text { Número } \\
\text { de } \\
\text { fillhos }\end{array}$ & $\begin{array}{c}\text { Tempo } \\
\text { de } \\
\text { empresa }\end{array}$ \\
\hline E 1 & 45 & Casada & Construção & $\begin{array}{l}\text { Superior } \\
\text { completo }\end{array}$ & 2 & 5 anos \\
\hline E 2 & 56 & $\begin{array}{c}\text { Casada }-2 \\
\text { vezes }\end{array}$ & Imobiliária & $\begin{array}{l}\text { Superior } \\
\text { completo }\end{array}$ & 3 & 17 anos \\
\hline E 3 & 45 & Casada & $\begin{array}{c}\text { Laboratório de } \\
\text { análise e } \\
\text { pesquisas clinicas }\end{array}$ & $\begin{array}{l}\text { Superior } \\
\text { completo }\end{array}$ & 2 & 18 anos \\
\hline E 4 & 40 & Casada & Publicidade & $\begin{array}{l}\text { Superior } \\
\text { completo }\end{array}$ & 3 & 19 anos \\
\hline E 5 & 50 & $\begin{array}{l}\text { Casada - } \\
\text { duas vezes }\end{array}$ & Buffet & Pós graduação & 0 & 15 anos \\
\hline E 6 & 58 & Viúva & Consultoria RH & Especialização & 2 & 20 anos \\
\hline E 7 & 41 & Casada & $\begin{array}{c}\text { Consultoria RH / } \\
\text { Professora }\end{array}$ & Pós graduação & 0 & 12 anos \\
\hline E 8 & 46 & Casada & $\begin{array}{c}\text { Decoração de } \\
\text { festa }\end{array}$ & $\begin{array}{l}2 \text { grau / curso } \\
\text { técnico }\end{array}$ & 4 & 5 anos \\
\hline E 9 & 69 & $\begin{array}{l}\text { Divorciada } \\
\text { / viúva }\end{array}$ & $\begin{array}{c}\text { Decoração de } \\
\text { festa }\end{array}$ & Normal & 3 & 5 anos \\
\hline E 10 & 31 & Casada & Escola de idiomas & $\begin{array}{c}\text { Superior } \\
\text { incompleto }\end{array}$ & 2 & 5 anos \\
\hline E 11 & 43 & Casada & $\begin{array}{c}\text { Transporte } \\
\text { escolar }\end{array}$ & $\begin{array}{l}\text { Superior } \\
\text { completo }\end{array}$ & 2 & 10 anos \\
\hline
\end{tabular}


Tabela 1 - Perfil das empreendedoras

\begin{tabular}{|c|c|c|c|c|c|c|}
\hline $\begin{array}{c}\text { Entre- } \\
\text { vistadas }\end{array}$ & Idade & $\begin{array}{c}\text { Estado } \\
\text { civil }\end{array}$ & $\begin{array}{l}\text { Ramo de } \\
\text { atuação }\end{array}$ & Escolaridade & $\begin{array}{c}\text { Número } \\
\text { de } \\
\text { filhos }\end{array}$ & $\begin{array}{c}\text { Tempo } \\
\text { de } \\
\text { empresa }\end{array}$ \\
\hline E 12 & 36 & Casada & $\begin{array}{l}\text { Escola de } \\
\text { computação } \\
\text { gráfica }\end{array}$ & Mestrado & 2 & 5 anos \\
\hline E 13 & 45 & Casada & Vestuário & Pós graduação & 2 & 8 anos \\
\hline E 14 & 62 & Divorciada & Casa para idosos & Pós graduação & 3 & 20 anos \\
\hline E 15 & 51 & Casada & Comunicação & Pós graduação & 1 & 20 anos \\
\hline E 16 & 35 & Casada & Academia & $\begin{array}{l}\text { Pós graduação } \\
\text { (em curso) }\end{array}$ & 0 & 8 anos \\
\hline E 17 & 32 & Solteira & $\begin{array}{l}\text { Produção de } \\
\text { eventos }\end{array}$ & Pos graduação & 0 & 5 anos \\
\hline E 18 & 54 & Separada & $\begin{array}{l}\text { Academia de } \\
\text { pilates }\end{array}$ & Pos graduação & 3 & 10 anos \\
\hline E 19 & 50 & Separada & $\begin{array}{c}\text { Agencia de } \\
\text { turismo }\end{array}$ & Pos graduação & 2 & 22 anos \\
\hline E 20 & 69 & Viúva & $\begin{array}{l}\text { Empresa de } \\
\text { recrutamento e } \\
\text { seleção } \\
\end{array}$ & $\begin{array}{l}\text { Superior } \\
\text { completo }\end{array}$ & 3 & 25 anos \\
\hline E 21 & 61 & Casada & Restaurante & Pos graduação & 2 & 5 anos \\
\hline E 22 & 46 & Casada & Bar & 2 grau & 2 & 8 anos \\
\hline E 23 & 40 & Casada & Restaurante & 2 grau & 2 & 19 anos \\
\hline E 24 & 45 & Casada & Restaurante & 2 grau & 2 & 8 anos \\
\hline E 25 & 34 & Solteira & $\begin{array}{c}\text { Consultoria de } \\
\text { RH }\end{array}$ & $\begin{array}{l}\text { Superior } \\
\text { completo }\end{array}$ & 0 & 11 anos \\
\hline
\end{tabular}

Fonte: Elaborado pelos autores.

\subsection{As Três Paredes de Vidro}

A conquista dos espaços da rua trouxe consigo algumas implicações para a vida pessoal e profissional dessas mulheres. Por exemplo, quando estão trabalhando em determinados espaços, antes ocupados apenas pelos homens, precisam provar que são competentes, como retratado a seguir por E11, 43 anos, dona de uma empresa de transporte escolar:

Quando eu descia da van, eu sempre fui muito pequena, de salto, todo mundo falava: gente mas isso não combina com você. As pessoas falam comigo: mas você não dirige não, né? Você só administra, não é? Eu falo, eu dirijo. E quando perguntam: quem leva a van para o mecânico? É uma surpresa quando eu falo, eu.

A mesma entrevistada relata que hoje é comum encontrarmos mulheres na rua dirigindo vans, mas que há 27 anos, por exemplo, ela percebia que os homens paravam de fazer as suas atividades para ver se ela dava conta de manobrar o carro. Esta empreendedora da área do 
transporte diz que sua estratégia para vencer foi dominar o que faz, praticar muito e ficar muito boa, tanto na direção das vans quanto na coordenação de sua equipe.

Não são todas as mulheres entrevistadas que se sentem totalmente confortáveis nos espaços da rua, como explica a E7, 41 anos, casada, consultora de RH e professora. Ela relata seus receios no exercício dessa atividade: "Até mesmo dando aula, quando a turma é masculina, eu falo: Ah, meu Deus, com esse tanto de homem aqui na frente, e eu que vou ter o papel de ensinar? Eu vou dar conta disso?". Esta fala, ao mesmo tempo em que demonstra o desconforto ao atuar em uma profissão onde a presença feminina é significativa, dá indícios de que essa empreendedora questiona a própria capacidade, ou seja, pode revelar a insegurança ao ocupar um lugar, em uma situação específica que a faz se sentir inferior por ser mulher. Portanto, o desconforto desta empreendedora não está relacionado ao fato de lecionar, mas sim, lecionar para um grupo exclusivamente masculino. Para conquistar este espaço masculino ela relata, ainda, a necessidade de mudar de postura: "Como o mundo é muito masculino dos empresários, a gente acaba ficando um pouco masculina, com atitudes, posturas, para conseguir ganhar o jogo”.

Percebe-se a existência de cenários mais propícios ao empreendedorismo feminino, como, por exemplo, o ramo da moda e da beleza, enquanto as mulheres que empreendem em ramos mais masculinizados, como o aluguel de vans, por exemplo, tendem a enfrentar mais dificuldades em suas atividades. Isso corrobora a literatura sobre os guetos profissionais femininos (ROCHA-COUTINHO, 1994; ABRAMO, 2000; BRUSCHINI, 2000; BRUSCHINI, LOMBARDI, 2001) ainda presentes nos dias atuais.

A discriminação parece ser o que sustenta as paredes e, portanto, é uma das principais implicações da carreira empreendedora para as mulheres, podendo partir, inclusive, de seus próprios familiares. A entrevistada E5, que já foi casada duas vezes e não possui fillhos, empreendeu aos 45 anos, quando decidiu abrir um buffet, aproveitando sua formação em gastronomia. Porém, em sua fala fica retratada a dificuldade: "É muito difícil para a gente ser mulher, empreendedora, empresária e sozinha. Eu tenho que provar sempre”. Ela sente que seus cunhados homens, principalmente, não levam a sério sua nova profissão.

Isso também é relatado por E6, 58 anos, viúva, dona de uma empresa de Recursos Humanos: "Quando eu montei falei para o meu cunhado: eu estou montando uma empresa... 'hahahaha... Pode montar quantas você quiser'. Hoje eu estou montando uma sede em Londres [...] Todo mundo acha que você está brincando e que você vai voltar para casa”. Esses relatos demonstram o quanto os papéis femininos e masculinos são padrões criados pela sociedade e 
que definem os comportamentos. Conforme ressalta a literatura (LOURO, 2013) é através destes papéis que se difere o que é adequado ou não para uma mulher.

Entretanto, na maioria das vezes, a discriminação é praticada por pessoas que possuem contato direto com o trabalho da mulher empreendedora, como, por exemplo, clientes e fornecedores. A empreendedora E1 tem 45 anos, é casada e tem duas filhas adultas. Ela trabalhava em uma loja de materiais de construção que pertencia a seus pais, e em um determinado momento ela teve a oportunidade de seguir sozinha com o negócio, pois este não era de interesse de suas irmãs. Por esse motivo, ela sempre enfrentou dificuldades por estar à frente de um empreendimento considerado mais apropriado para homens. No entanto, ela não se deixou vencer pelas barreiras, e acabou fortalecendo-se no ramo e trazendo suas filhas para junto de si no trabalho.

A filha mais velha não se adaptou às atividades e seguiu outros caminhos profissionais, enquanto a mais nova continua ao seu lado tocando o negócio. A empreendedora relata que mudou seu comportamento a ponto de conseguir identificar, em si mesma, traços mais masculinos, os quais a favorecem na lida com os clientes, no dia-a-dia. Mas, percebe que sua filha mais nova, mesmo entendendo do negócio, ainda é discriminada e não sabe como enfrentar essa situação: "embora tenha um bom conhecimento sobre os materiais vendidos na loja, alguns clientes pedem para que um atendente homem venha atendê-los e não ela”.

Fica evidente nesse relato que ela, para não perder um bom cliente, abre mão de conduzir explicitamente a negociação. Ou seja, em vez de posicionar-se como vítima, ela age conscientemente, articulando uma saída para a situação de discriminação.

Enquanto algumas empreendedoras agem através de uma estratégia de não reagir abertamente ao machismo, outras optam por assumir uma postura diferente, enfrentando a discriminação e reconhecendo a necessidade de provar seu valor, de provar que dão conta do recado.

$\mathrm{Na}$ tentativa de conquistar seu espaço e provar o seu valor diante da sociedade, essas mulheres enfrentam, constantemente, situações que evidenciam a discriminação. Não foi incomum ouvir das entrevistadas frases como: "Eles não te respeitam", "Eles não te dão crédito", "Essa mulher não sabe de nada". Sendo assim, essa discriminação percebida por elas reflete o pensamento machista que ainda acompanha a sociedade nos dias atuais.

Nesta pesquisa, os achados sobre o que os homens pensam sobre as empreendedoras, conforme as frases anteriormente apresentadas, corroboram a literatura que trata dos valores externos que podem contribuir para aumentar a barreira que evita o crescimento das mulheres. 
Valores estes que são as opiniões que os homens têm das características das mulheres (DAVIES-NETZLEY, 1998). Apesar de alguns autores (BARBOSA, ROCHA-COUTINHO, 2012) ressaltarem o aparecimento de flexibilidade em relação aos papéis masculinos/femininos, ainda assim é possível verificar discriminação, mesmo que sutil, quando o feminino não está realizando atividades do modelo tradicional: mulher-mãe-esposa-do lar.

\subsection{Possibilidades de Rompimento das Barreiras}

Certamente, a carreira empreendedora para a mulher maximiza a percepção de independência financeira. Afinal, o risco inerente à atividade vem acompanhado de ganhos financeiros que podem ser superiores àqueles auferidos por seus companheiros. Isso ficou evidente na pesquisa realizada, sendo que algumas mulheres relataram mudanças nas relações familiares, a partir do momento em que se perceberam como donas do próprio dinheiro. É o caso de E2, que já foi casada duas vezes e tem 56 anos, dona de uma imobiliária: "Na medida em que as mulheres passaram a ganhar o dinheiro, isso muda a história familiar. O poder está no dinheiro, quando entra o dinheiro o poder é dividido!"

A mudança na história familiar pode ser compreendida como a transformação das relações. Se antes a mulher se percebia com pouca autonomia, após empreender fica claro o seu empoderamento. Ao dividir as despesas, essas mulheres passaram a ter a possibilidade de dividir também o poder dentro de suas casas, abandonando uma postura passiva para assumir uma posição mais ativa, participando com mais poder nas decisões do casal.

Acostumados a serem provedores, como antigamente, muitos homens ainda não veem com bons olhos suas esposas à frente de um negócio próprio. Sobretudo, porque o empreendimento proporciona a elas a independência por meio do dinheiro. Consumir utilizando o próprio dinheiro é quase sinônimo de ser livre, e esse fato também é narrado pelas mulheres empreendedoras, como E3:

\footnotetext{
Então as mulheres começaram por uma necessidade de ter seu o próprio dinheiro, porque hoje em dia está muito forte a resistência a ser submissa, elas não querem pedir dinheiro, não querem o homem controlando a vida da mulher: me dá dinheiro para fazer unha, me dá dinheiro para colocar crédito no celular? E ele controlava a sua vida. Porque quem tem dinheiro controla, não é?
}

Essa situação de ser controlada, descrita por uma das empreendedoras, se revela incômoda por reforçar a dependência da mulher em relação ao homem. Ainda assim, não é incomum ouvir relatos de mulheres que entregam o próprio salário aos maridos ou que não 
admitem ganhar mais do que eles. Nesse sentido, fica evidente o machismo que ainda marca as relações entre homens e mulheres nos dias atuais.

É importante destacar que essa mentalidade machista nem sempre é masculina, ou seja, há mulheres que, de fato, não acham aceitável terem uma remuneração superior à de seus companheiros. Isso porque, talvez inconscientemente, elas ainda atribuam a seus maridos o papel de provedores do lar.

Ainda assim, destaca-se que a independência financeira foi relatada como um dos principais fatores que auxiliam as mulheres a quebrar as paredes da discriminação. Ficou evidente que os retornos financeiros alcançados por meio do empreendimento conferem às mulheres reconhecimento social. Esse resultado corrobora a literatura, já que o reconhecimento social é uma das maiores satisfações das empreendedoras (KORN, FERRY, 2002; BARBOSA et al, 2011)

A mulher empreendedora é reconhecida, na maioria das vezes, apenas quando a empresa atinge uma fase mais sólida, indicando que a mulher "conseguiu". Machado (2012) já ressaltava que a admiração vai ocorrer somente quando o negócio atinge fases mais sólidas. Outro dado é que o fato de ela "conseguir" é algo que ainda surpreende algumas pessoas, reforçando a reflexão: se um homem "conseguir" é considerado normal, por que para uma mulher seria considerado "anormal"?

Ser uma mulher de negócios aumenta a credibilidade da mulher e ela começa a ter mais poder na sociedade. Ser empreendedora muda a visão dos homens em relação a elas. Isso foi relatado por várias empreendedoras, como E13, 45 anos, dona de uma loja de roupas, que, inclusive, enxerga o fato de ser empreendedora como um diferencial em relação às outras mulheres: "Hoje eu acho que é um diferencial sim. Com certeza, quando você chega em um ambiente masculino, você sendo empreendedora, dá um respeito maior. Muda, sim”. Para essa empreendedora, o fato de empreender já demonstra características diferenciadas, tais como: coragem e otimismo. "A pessoa já se diferencia. Como mulher, mais ainda".

Além de receber o reconhecimento de suas realizações pela sociedade, as entrevistadas relatam, também, o orgulho que proporcionam à sua família por estarem à frente de um negócio. E4 explica: "Meu marido me acha o máximo. Me vê como uma empreendedora".

A empreendedora E25, 34 anos, está à frente de uma consultoria de Recursos Humanos e percebe admiração por parte das pessoas, sentindo-se reconhecida pelo que faz: "Eu percebo que algumas pessoas que já trabalharam comigo ou até minha família tem um orgulho mesmo, de ter alguém à frente de um negócio". Frases como "eu ajudo as outras a caminhar", "É bom 
poder trazer alguma referência para outras mulheres, fazer com que as pessoas me tenham como uma influência boa" também apareceram.

$\mathrm{O}$ reconhecimento é mais importante para aquelas que percebem e descreveram explicitamente a discriminação no mercado, sentindo-se deslumbradas ao serem admiradas. Já aquelas que não relataram discriminação, ou seja, enfocando a paridade entre os gêneros, não demonstraram o mesmo entusiasmo, mas quando são reconhecidas, é gratificante. A busca pelo reconhecimento também esteve mais presente naquelas mulheres que empreenderam em um setor onde há maior dominação masculina.

Sendo assim, para essas mulheres não basta ter o reconhecimento apenas por ser dona de casa ou uma boa mãe. Elas querem mais. Os relatos evidenciam a satisfação em ser dona do próprio negócio, em alcançar um espaço que um dia the foi negado. Dessa forma, o reconhecimento social está atrelado às suas experiências profissionais.

As estratégias utilizadas por elas para quebrar as paredes de vidro estão relacionadas a dedicação e muito trabalho. "Se a gente não correr atrás, não tem". Algumas ressaltaram a importância de mudarem algumas características: "A gente acaba ficando um pouco masculina, com atitudes, posturas para ganhar o jogo. Essa era a forma que eu tinha para ser combativa e vencer, ganhar". Outra empreendedora diz da importância de algumas características independentemente do gênero: " Pra mim, para ser empreendedora a pessoa tem que ser agressiva. As pessoas mais agressivas pensam mais a frente, não esbarram nas dificuldades que aparecem". Outra coloca a importância de encontrar mulheres empreendedoras que "deram certo" para observar e fazer igual.

A Figura 1 sintetiza as paredes de vidro encontradas pelas mulheres empreendedoras e suas estratégias para quebrá-las. Para as empreendedoras entrevistadas, a família, os clientes e os fornecedores, bem como os amigos, vizinhos e conhecidos podem, de forma sutil, reforçar o preconceito em relação à mulher empresária, contribuindo assim para o crescimento de barreiras em relação ao seu crescimento. Na visão dessas mulheres, foi a partir de muito trabalho que a independência financeira chegou. Tanto a independência financeira quanto o reconhecimento social influenciam de forma positiva a vida dessas mulheres e ajudam a quebrar estas três barreiras. 


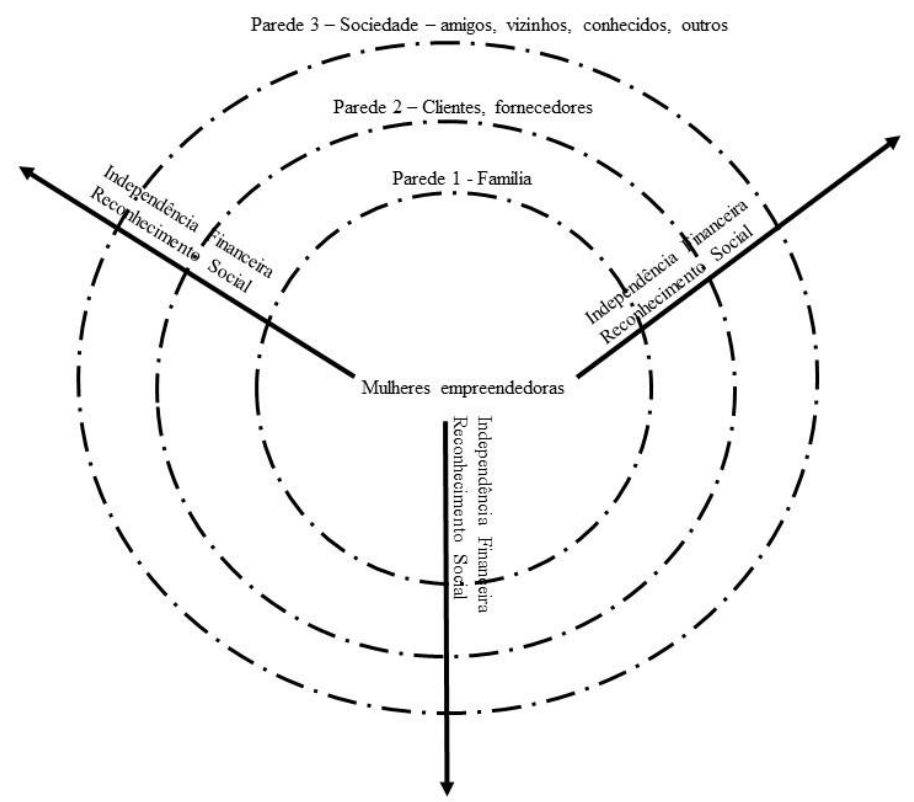

Fonte: Elaborado pelos autores.

\section{CONSIDERAÇÕES FINAIS}

Neste trabalho foram identificadas três paredes que cercam a carreira da mulher empreendedora, o que reforça a evidência já ressaltada na literatura de que, apesar de essa atividade trazer uma oportunidade mais flexível para a mulher lidar com os aspectos da vida pessoal e profissional, é ainda uma atividade tipicamente masculina (MACHADO, 2012) e que impõe muitas barreiras para serem quebradas (CRAMER et al., 2012).

A primeira parede que se encontra mais próxima da mulher é a família. Para rompê-la é necessário enfrentar marido, pais, irmãos, cunhados e filhos. Ela assume os riscos do empreendimento mesmo não encontrando apoio entre seus familiares. A família é uma parte da sociedade e, por essa razão, muitas vezes reproduz a discriminação e o machismo em relação às mulheres.

A segunda parede é constituída pelos clientes, fornecedores, funcionários e demais pessoas que se relacionam profissionalmente com as empreendedoras. Algumas empreendedoras perceberam surpresa por parte desses grupos quando eles notavam que era uma mulher que conduzia o negócio. Ou seja, não era esperado por eles que uma mulher estivesse à frente da situação.

A terceira parede é representada pela sociedade de maneira geral. Contempla todas aquelas pessoas que não se relacionam diretamente com à empreendedora, ou seja, amigos, 
vizinhos e proprietários de outros empreendimentos. Todas essas pessoas auxiliam na construção e reforçam os estereótipos masculinos e femininos, e portanto, contribuem para as situações de discriminação das mulheres no mercado de trabalho.

O diferencial deste trabalho foi encontrar barreiras que ultrapassam as já discutidas em outras pesquisas com empreendedoras, sendo que o reconhecimento e a independência financeira influenciam essa dinâmica de forma positiva. Vários estudos ressaltam a família como uma força impeditiva para o crescimento ou manutenção do empreendimento (TEIXEIRA; BONFIM, 2016; MACHADO, 2009), mas não tratam de barreiras encontradas em outras situações.

Foi possível compreender que as mulheres empreendedoras lidam mais com as barreiras associadas à teoria "Glass Walls" encontrada na literatura a partir de Miller, Kerr e Reid (1999) e que, para combatê-las, elas se prendem à independência financeira, uma vez que a carreira empreendedora maximiza a possibilidade dessa independência. $\mathrm{O}$ risco à atividade vem acompanhado de possibilidades de ganhos financeiros que podem ser superiores àqueles auferidos por seus companheiros. Quando isso acontece, percebe-se o empoderamento, através das falas das empreendedoras. A independência financeira foi relatada como um grande fator que auxilia a mulher a quebrar as paredes. Além disso, os retornos financeiros por meio do empreendimento conferem às mulheres reconhecimento social. A admiração também vai ocorrer apenas quando o negócio já está solidificado. O reconhecimento social e o fato da admiração aparecer com o negócio já solidificado são aspectos que já foram ressaltados pela literatura a partir de Machado (2012) e Korn e Ferry (2002).

É interessante observar o quanto a experiência pessoal e subjetiva dessas mulheres ultrapassa a própria realidade e é percebida como um fenômeno social. Ao narrarem suas histórias, elas falam em nome de todas as mulheres. Isso mostra como as histórias individuais podem espelhar a sociedade e vice-versa. Além disso, demonstra como o contexto sociocultural exerce uma força negativa, que apesar de ser sutil pode ter impacto na vida destas mulheres.

Outro aspecto importante é como devemos avançar nos estudos sobre a mulher e suas possibilidades de trabalho. O estudo demonstrou o quanto as mulheres estão envolvidas com outros papéis, além dos papéis do lar, e o quanto estar neste outro lugar gera reconhecimento, mas, também e inicialmente, quebra de barreiras. Para Cappelle et al. (2007), os estudos nessa área precisam superar limitações, tais como: por que e como determinados elementos históricos vinculados ao homem e/ou a mulher perpassam as práticas de gestão? Buscou-se aqui tratar de elementos sociais que perpetuam ou visam perpetuar o papel da mulher vinculado apenas ao 
espaço da casa. A questão que fica é: podemos falar de papéis apenas masculinos e apenas femininos?

Corrobora-se Louro (2013) na medida em que se torna preciso entender a identidade do sujeito como algo fluido, ou seja “ ... identidades que se transformam, que não são fixas ou permanentes, que podem, até mesmo, ser contraditórias" (LOURO, 2013, p.28).

Espera-se, através deste estudo, contribuir, em termos práticos, para uma maior conscientização da presença de barreiras na carreira das mulheres, não só das executivas, ou seja, mulheres que estão nas organizações, mas em outro contexto, no empreendedorismo. Logo, as contribuições deste artigo estão em descrever o quanto as barreiras para o crescimento profissional podem estar presentes na vida das mulheres em situações diferentes, mas também o quanto elas podem vivenciar aspectos positivos na vida profissional. 


\section{REFERÊNCIAS}

ABRAMO, L. W. A situação da mulher latino-americana. In: DELGADO, D. G.; CAPPELLIN, P; SOARES, V. Mulher e trabalho: experiências de ação afirmativa. Boitempo editorial, 2000.

ANDRADE, S. R. "Eu sou uma pessoa de tremendo sucesso!": trajetórias, identidades e representações de mulheres executivas. In: ENCONTRO NACIONAL DE HISTÓRIA ORAL, 10., 2010, Recife. Anais... Recife: Centro de Filosofia e Ciências Humanas, 2010.

ANDRADE, L. F. S.; MACEDO, A. dos S.; OLIVEIRA, M. de L. S. A produção científica em gênero no Brasil: um panorama dos grupos de pesquisa de administração. RAM - Revista Adm. Mackenzie, São Paulo, v. 15, n. 6, Edição Especial, p.48-75, nov./dez. 2014.

BADINTER, E. Um é o outro: relações entre homens e mulheres. Rio de Janeiro: Nova Fronteira, 1986.

BARBOSA, P. Z.; ROCHA-COUTINHO, M. L. Ser mulher hoje: a visão de mulheres que não desejam ter filhos. Psicologia \& Sociedade, v. 24, n. 3, p. 577-587, 2012.

BARBOSA, F. C.; CARVAlHO, C. F.; SIMOES, G. M. M.; TEIXEIRA, R. M. Empreendedorismo feminino e estilo de gestão feminina: estudo de casos múltiplos com empreendedoras na cidade de Aracajú - Sergipe. Revista da Micro e Pequena Empresa, Campo Limpo Paulista, v. 5, n. 2, p. 124-141, maio/ago, 2011.

BARDIN, L. Análise de conteúdo. São Paulo: Edições 70, 2011.

BEAUVOIR, S. O segundo sexo. Rio de Janeiro: Nova Fronteira, 1980.

BETIOL, M. I. S.; TONELLI, M. J. A mulher executiva e suas relações de trabalho. Revista de Administração de Empresas, São Paulo, v. 31, n.4, p. 17-33, out./dez. 1991.

BONFIM, L. C. S.; TEIXEIRA, R. M. Empreendedorismo feminino: desafios enfrentados por empreendedoras na gestão de pequenos negócios no setor de turismo. RPCA - Revista Pensamento Contemporâneo em Administracão, Rio de Janeiro, v. 9, n. 2, p. 48-69, abr.jun. 2015.

BOTELHO, L. de L. R.; MACEDO, M.; FIALHO, F. A. P. "Glass Ceiling” em empresas intensivas em conhecimento: desafios enfrentados por executivas em suas ascensões profissionais. In: ENCONTRO NACIONAL DE ENGENHARIA DE PRODUÇÃO, 30., 2010, São Carlos. Anais... São Carlos, 2010.

BROWN, M. L. Examining leadership and the laminated glass ceiling: gender and leadership traits. Graduate Faculty of the School of Business and Technology Management, 2010.

BRUSCHINI, C. Gênero e trabalho no Brasil: novas conquistas ou persistência da discriminação? (Brasil, 1985/95). In: ROCHA, M. I. B. Trabalho e gênero: mudanças, permanências e desafios. Campinas: ABEP, NEPO/UNICAMP e CEDEPLAR/UFMG/ São Paulo: Ed.34, 2000. 
BRUSCHINI, C.; LOMBARDI, M. R. Instruídas e trabalhadeiras: trabalho feminino no final do século XX. Cadernos Pagu, n. 17/18, p.157-196, 2001.

CAPPELlE, M. C. A.; BRITO, M. J.; MELO, M. C. de O.; VASCONCELOS, K. A. A produção científica sobre gênero nas organizações: uma meta-análise. REAd - Revista Eletrônica de Administração, Porto Alegre, Edição 57, v. 13, n. 3, set./dez., 2007.

CARVALHO NETO, A.; TANURE, B.; MOTA-SANTOS, C. M. Pride and prejudice beyond the glass ceiling: Brazilian female executives psychological type. Revista de Ciências da Administração, Florianópolis, v. 16, n. 39, p. 210-223, ago. 2014.

CRAMER, L.; CAPPELlE, M. C. A; ANDRADE, A. L. S.; BRITO, M. J. Representações femininas da ação empreendedora: uma análise da trajetória das mulheres no mundo dos negócios. Revista de Empreendedorismo e Gestão de Pequenas Empresas, v. 1, n. 1, p. 1$15,2012$.

COELHO, D. Ascensão profissional de homens e mulheres nas grandes empresas brasileiras. In: NEGRI, J. A.; NEGRI, F.; COELHO, D. Tecnologia, exportação e emprego. IPEA, Brasília, 2006.

DaMATTA, R. A casa \& a rua. Espaço, cidadania, mulher e morte no Brasil. Rio de Janeiro: Guanabara Koogan, 1991.

DaMATTA, R. O que faz o brasil, Brasil? Rio de Janeiro: Rocco, 1986.

DAVIDSON, M. J.; COOPER, C. L. Shattering the glass ceiling: the woman manager. London: Paul Chapman Publishing Ltd, 1992.

DAVIES-NETZLEY, S. A. Women above tge Glass Ceiling: perceptions on corporate mobility and strategies for success. Gender \& Society, v. 12, n. 3, p. 339-355, 1998.

DELLAGNELO, E. H. L.; SILVA, R. C. Análise de conteúdo e sua aplicação em pesquisa na administração. In: VIEIRA, M. M. F.; ZOUAIN, D. M. (orgs). Pesquisa qualitativa em administração: teoria e prática. Rio de Janeiro: FGV, 2005.

FABRICIO, J. S.; MACHADO, H. V. Dificuldades para criação de negócios: um estudo com mulheres empreendedoras no setor do vestuário. Revista Gestão e Planejamento, Salvador, v. 12, n. 3, p. 515-529, set./dez. 2012.

FLICK, U. Introdução à pesquisa qualitativa. Porto Alegre: Artmed, 2009.

GOMES, A. F.; SANTANTA, W. G. P.; ARAÚJO, U. P. Empreendedorismo feminino: o estado-da-arte. In: ENCONTRO ANUAL DA ANPAD, 33., 2009, São Paulo. Anais... Rio de Janeiro, ANPAD, 2009.

GOMES, D. T.; GUERRA, P. V.; VIEIRA, B. N. O desafio do empreendedorismo feminino. In: ENCONTRO ANUAL DA ANPAD, 35., 2011, Rio de Janeiro. Anais... Rio de Janeiro, ANPAD, 2011. 
JONATHAN, E. G. Mulheres Empreendedoras: Medos, Conquistas e Qualidade de Vida. Psicologia em Estudo, Maringá, v. 10, n. 3, p. 373-382, set./dez. 2005.

JONATHAN, E. G. Mulheres empreendedoras: o desafio da escolha do empreendedorismo e o exercício do poder. Revista Psicologia Clinica, Rio de Janeiro, v. 23, n. 1, p.65-85, 2011.

LIMA, G. S.; CARVALHO NETO, A. ; LIMA, M. S.; TANURE, B.; VERSIANI, F. O teto de vidro das executivas brasileiras. Pretexto, Belo Horizonte, v. 14, n. 4, p.65-80, out./dez., 2013.

LOURO, G. L. Gênero, sexualidade e educação. Uma perspectiva pós-estruturalista. Petrópolis: Vozes, 2013.

MACHADO, F. B. Dilemas de Mulheres Empreendedoras em Empresas Inovadoras Nascentes. In: ENCONTRO ANUAL DA ANPAD, 36., 2012, Rio de Janeiro. Anais... Rio de Janeiro, ANPAD, 2012.

MACHADO, H. V. Identidade de mulheres empreendedoras. Maringá: Eduem, 2009.

MATTAR, F. Pesquisa de marketing: metodologia, planejamento. 5. ed. São Paulo: Atlas, 1999.

MELO, É. Feminismo: velhos e novos dilemas uma contribuição de Joan Scott. Cadernos Pagu, Campinas, n. 31, p. 553-564, jul./dez. 2008.

MILLER, W.; KERR, B.; REID, M. A national study of gender-based occupational segregation in municipal bureaucracies: persistence of glass walls? Public Administration Review, v. 59, n.3, p. 218-230, may/june 1999.

MOORE, D. P.; BUTTNER, E. Holly. Women entrepreneurs: moving beyond the glass ceiling. New Delhi: Sage publications, 1997.

MORRISON, A M.; WHITE, R. P.; VELSOR, E. V. Breaking the glass ceiling: can women reach the top of America's largest corporations? Massachusetts: Updated edition, 1994.

MORRISON, A. M.; GLINOW, M. A. V. Women and minorities in management. American Psychologist, v. 45, n. 2, p. 200-208, 1990.

MOTA-SANTOS, C. M.; TANURE, B.; CARVALHO NETO, A. O percurso do trabalho feminino no Brasil: vestígios dos primórdios no presente. In.: ANDRADE, J. O., CARVALHO NETO, A. Mulheres profissionais e suas carreiras sem censura. São Paulo: Atlas, 2015.

MOTA-SANTOS, C.; TANURE, B.; CARVALHO NETO, A. Mulheres executivas brasileiras: o teto de vidro em questão. Revista Administração em diálogo - RAD, São Paulo, v. 16, n. 3, p. 56-75, set./dez. 2014.

NEWMAN, M. A. Career advancement: does gender make a difference? The American Review of Public Administration, v. 23, n. 4, 1993.

RICHARDSON, R. J. Pesquisa social: métodos e técnicas. São Paulo: Atlas, 2007. 
ROCHA-COUTINHO, M. L. Tecendo por trás dos panos: a mulher brasileira nas relações familiares. Rio de Janeiro: Rocco, 1994.

SILVA, J. C.; DAL MAGRO, C.; SILVA, M. Z. Gender inequality accounting profession from the perspective of the glass ceiling. RACE - Revista de Administração, Contabilidade e Economia, Joaçaba, v. 15, n. 2, p. 447-474, maio/ago. 2016.

SOUZA, F. M.; VOESE, S. B.; ABBAS, K. Mulheres no topo: as contadoras paranaenses estão rimpendo o glass ceiling? Advances in Scientific and Applied Accounting, São Paulo, v. 8, n. 2, p.244-270, maio/ago. 2015.

STEIL, A. V. Organizações, gênero e posição hierárquica - compreendendo o fenômeno do teto de vidro. Revista de Administração, São Paulo, v. 32, n. 3, p. 62-69, jul./set. 1997.

TEIXEIRA, R. M.; BONFIM, L. C. S. Empreendedorismo feminine e os desafios enfrentados pelas empreendedoras para conciliar os conflitos trabalho e familia: estudo de casos múltiplos em agências de viagens. Revista Brasileira de Pesquisa em Turismo, São Paulo, v. 10, n. 1, p. 44-64, jan./abr. 2016.

VALE, G. M. V.; SERAFIM, A. C. F. Embeddedness, Empreendedorismo e Gênero: desafios para tornar forte o sexo frágil. In: ENCONTRO ANUAL DA ANPAD, 34., 2010, Rio de Janeiro. Anais... Rio de Janeiro, ANPAD, 2010.

VINUTO, J. A amostragem em bola de neve na pesquisa qualitativa: um debate em aberto. Temáticas, Campinas, v. 22, n., 44, p. 203-220, ago./dez. 2014.

WRIGHT, E. O; BAXTER, J. The glass ceiling hypothesis: a reply to critics. Gender \& Society, v. 14, n. 6, p. 914-821, 2000. 